\title{
Aging Well in an Upscale Retirement Community: The Relationships Among Perceived Stress, Mattering, and Wellness
}

\section{Jane E. Myers and Suzanne Degges-White}

Residents $(\mathrm{N}=142)$ of a southeastern, upscale retirement community completed measures of wellness, perceived stress, and mattering. Participants scored higher than did a group of adults under age 60 on 4 of 5 second-order wellness factors and Total Wellness, with medium to large effect sizes. Implications for counselors are discussed.

It is well known that over the course of the last 100 years, the life span of individuals in the United States and elsewhere has increased dramatically. Americans lived to be only 47 at the turn of the 20 th century and comprised 1 in 25 persons. In contrast, by the year 2000, the average life span had almost doubled, and persons over 60 comprised 1 in every 8 individuals (U.S. Administration on Aging, 2005). Less well known but equally dramatic has been the shift from viewing old age as a time of near universal distress, decline, disease, and depression to a new view of healthy aging captured in "the new mantra ... aging well," "positive aging, . . successful aging, ... [and] resourceful aging" (Anhus \& Reeve, 2006, p. 137). Concomitant with this paradigm shift is the need to focus empirical studies "on those persons who are aging well” (Peel, McClure, \& Bartlett, 2005, p. 299).

The World Health Organization (1952) defined health as more than the absence of disease, reflecting a positive perspective that incorporates physical, mental, and social well-being. To understand health in the older population, then, the emphasis in measurement needs to move away from morbidity and mortality to positive health and optimal aging (Peel et al., 2005). Within the counseling literature, models of holistic wellness have contributed to a better understanding of the factors involved in positive functioning for young (e.g., Myers \& Mobley, 2004) and midlife individuals (e.g., Degges-White \& Myers, 2006). Existing studies have illuminated the relationship between holistic wellness factors and a variety of other variables, such as perceived stress (Degges-White, Myers, Adelman, \& Pastoor, 2003; Powers, Myers, Tingle, \& Powers, 2004), caregiving stress (Myers,

Jane E. Myers, Counseling \& Educational Development, University of North Carolina at Greensboro; Suzanne Degges-White, Graduate Studies in Education, Purdue University Calumet. Correspondence concerning this article should be addressed to Jane E. Myers, Counseling o Educational Development, University of North Carolina at Greensboro,PO Box 26141, Greensboro,NC 27402-6171 (e-mail: jemyers@uncg.edu).

(1) 2007 by the American Counseling Association. All rights reserved. 
2003), marriage satisfaction (Myers, Madathil, \& Tingle, 2005), and mattering (Dixon Rayle \& Myers, 2004). To date, these models have not been applied to the older population (Myers, 2005; Myers \& Sweeney, in press).

A variety of definitions of wellness have been proposed. For example, Dunn (1961, 1977), the architect of the modern wellness movement, defined wellness as "an integrated method of functioning which is oriented toward maximizing the potential of which the individual is capable. It requires that the individual maintain a continuum of balance and purposeful direction within the environment where he is functioning" (Dunn, 1961, p. 4). Myers, Sweeney, and Witmer (2000), after reviewing literature from multiple disciplines, concluded that wellness is

a way of life oriented toward optimal health and well-being, in which body, mind, and spirit are integrated by the individual to live life more fully within the human and natural community. Ideally, it is the optimum state of health and well-being that each individual is capable of achieving. (p. 252)

This positive, holistic perspective is reflected in a number of models that present various components or characteristics of healthy persons as essential to functioning well. Common components of these models are social, emotional, intellectual, occupational, and spiritual wellness.

Myers and Sweeney (2005b, 2005d; Sweeney \& Myers, 2003) developed the Indivisible Self: An Evidenced-Based Model of Wellness (IS-Wel; see Figure 1) through structural equation modeling (see Hattie, Myers, \& Sweeney, 2004) and presented a tri-level factor structure to conceptualize the components of holistic wellness. A single, higher order total wellness factor, 5 second-order factors of the self, and 17 third-order factors compose this model, which has been used in multiple studies of wellness, including more than 30 doctoral dissertations and an equal number of independent studies (see Myers \& Sweeney, in press, for a review of wellness research). Their initial hypothesis that the wellness components are interrelated such that change in one area contributes to or causes changes in the other areas was supported by the tri-level factor structure and especially the strength of the higher order wellness factor.

Both love and social support have been linked empirically to greater physical health, health-related quality of life, longevity, and positive mental health and well-being across the life span (Myers et al., 2000). Given the strong correlation between physical and mental health (Larson, 1999), and the importance of social support for both, studies are needed that provide greater definition to social support factors and the relationship of these factors to holistic wellness. One such factor, mattering, was defined by Schlossberg, Lynch, and Chickering (1989) as the beliefs that people have (right or wrong) that they matter to someone else, that they are the objects of someone else's attention, and that others care about them and appreciate them. Such beliefs have a direct and positive effect on depression 


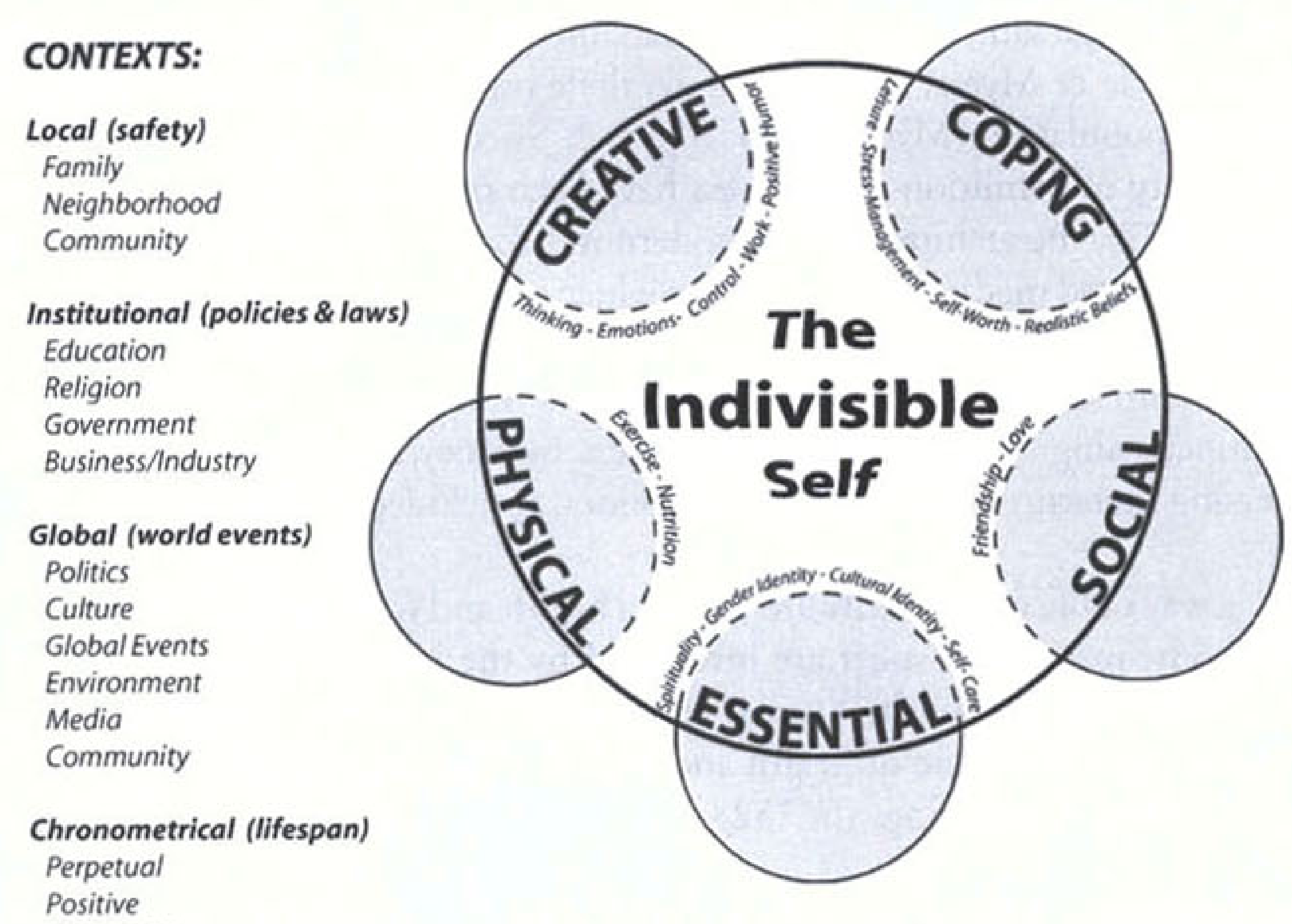

Purposeful

(C) T. L. Sweeney \& J.E.Myers, 2003.

FIGURE 1

\section{The Indivisible Self: An Evidence-Based Model of Wellness}

Note. Creative $=$ Creative Self; Coping $=$ Coping Self; Social $=$ Social Self; Essential $=$ Essential Self; Physical $=$ Physical Self. From The Indivisible Self: An Evidence-Based Model of Wellness, by T. J. Sweeney and J. E. Myers, 2003, Greensboro, NC: Author. Copyright 2003 by T. J. Sweeney and J. E. Myers. Reprinted with permission.

(Hagerty \& Williams, 1999). The importance of mattering was emphasized by H. R. Marcus and Kitayama (1991), who argued that sense of belonging is such a strong factor that relationships, as opposed to individual functioning, may be the most important variable in understanding human behavior.

The present study was undertaken to provide a profile of wellness among independent, older adults. We chose an upscale retirement community setting in the hopes of finding older adults of whom Atkinson and Hackett (1998) noted are experiencing higher incomes, greater vitality, and overall healthier lives than their counterparts in the last century. To build on existing studies with younger persons, two variables were added that seem relevant to the lives of older individuals. The first of these, perceived stress, was selected on the basis of multiple studies that have emphasized the significance of stress in the lives of older adults (e.g., Moos, Schutte, \& Brennan, 2005) and the inverse relationship between perceived stress and wellness (e.g., Powers et al., 2004). The second, mattering or belonging, was selected on the basis of the preponderance of evidence establishing a strong relationship between social support and mental health over the life span, particularly in later life (Blazer, 2005; Yue-Juan, Yun-Jing, \& Zeng-Qli, 2005). 
The primary research questions were as follows:

1. What are the levels of wellness, perceived stress, and mattering in the older adult participants?

2. What is the relationship among wellness, perceived stress, and mattering?

3. Are there differences in wellness, perceived stress, or mattering among the participants based on gender, age, ethnicity, or marital status?

4. Are there differences in wellness between the participants and an available norm group of younger adults?

\section{METHOD}

Participants were recruited from a large, upscale retirement community in a metropolitan area of the Southeast. The community provided options of apartments and villas for independent older adults, many of whom were retired from one of the universities in the local area. All participants were volunteers who completed the assessments individually and received a profile with their wellness scores as well as the opportunity to participate in a wellness workshop and to begin to develop a personal wellness plan.

\section{Participants}

Participants were recruited through the wellness committee of the retirement community. Due to the nature of the recruitment procedures, an accurate response rate could not be computed. A total of 142 residents completed surveys, and most participated in the wellness workshop. Among the respondents, $35.5 \%$ were men and $64.5 \%$ women. They ranged in age from 73 to 101 years, with a mean age of $83(S D=4.86)$. More than half $(54.2 \%)$ were married, $6.3 \%$ were single, and $37.3 \%$ were widowed. Most $(81 \%)$ were Caucasian, and $12.7 \%$ marked "other race" but did not specify what that meant. In terms of education, $13.4 \%$ completed high school, $16.9 \%$ completed 2 years of college or trade school, $36.6 \%$ had a bachelor's degree, $19.7 \%$ had a master's degree, and $7.7 \%$ had a doctoral or professional degree (e.g., MD, DDS).

\section{Instrumentation}

Participants completed the Five Factor Wellness Inventory (5F-Wel; Myers \& Sweeney, 2005a), the Perceived Stress Scale (PSS; Cohen, Kamarck, \& Mermelstein, 1983), the General Mattering Scale (GMS; Rosenberg \& McCullough, 1981), and a brief demographic scale.

5F-Wel (Myers \& Sweeney, 2005a). The 5F-Wel is a 73-item instrument developed through structural equation modeling (Hattie et al., 2004) designed to assess each of the factors in the IS-Wel (see Figure 1; Myers \& Sweeney, 2005d). Each item is a statement (e.g., "I am an active person") that requires a response on a 4-point Likert-type scale ranging from 4 (strongly agree) to 1 (strongly dis- 
agree). Scale scores are sums of the responses to each item in the scale. A linear transformation is used to place all scales on a common metric, with scores ranging from 25 to 100; higher scores indicate a higher level of wellness. The instrument provides scores for Total Wellness, a factor composed of the sum of all items in the scale, 5 second-order factors, and 17 third-order factors that group within the second-order factors as shown in Figure 1.

Myers and Sweeney (2005c) reported alpha coefficients ranging from .91 to .94 for the 5 second-order factors. The alphas in the present study were as follows: Total Wellness $=.94$, Creative Self $=.86$, Coping Self $=.78$, Social Self $=.82$, Essential Self $=.86$, and Physical Self $=.83$.

PSS (Cohen et al., 1983). The PSS was designed to measure the degree to which situations in one's life are appraised as stressful. Cohen et al. provided three versions of the PSS, including 14, 10, or 4 items, with comparable reliability for the various versions. The abbreviated PSS 4-item inventory (PSS4) was used in this study. The PSS4 items (e.g., "In the last month, how often did you feel unable to control important things?") are questions that are answered using a 5-point scale, from 0 (never) to 4 (very often). The PSS 4 was normed on two samples of college students totaling 446 individuals. Cohen et al. reported alpha and 2-week test-retest coefficients of .85; in the present study, the alpha coefficient was .50 .

GMS (Rosenberg \& McCullough, 1981). Rosenberg and McCullough defined mattering as the degree to which individuals perceive themselves to be important to others. The authors' research indicated that an individual's sense of mattering is not tied to others displaying only a positive opinion of the individual but to the belief that others care enough about the individual to have an opinion of him or her at all. Perceptions of mattering to others have been shown to be indicative of lessened physiological illness and distress (Amundsen, 1993; Rosenberg \& McCullough, 1981).

The GMS was developed by F. M. Marcus (1991) to assess individuals' feelings that they mattered to other people. The instrument consists of five Likert-type items (e.g., "How much do you feel others would miss you if you went away?") rated on a 4-point scale, from 1 (not at all) to 4 (very much). A higher score indicates a stronger sense of significance to others. DeForge and Barclay (1997) reported an alpha coefficient for this scale of .85 in a study of 199 men who were homeless; in the present study, the alpha coefficient was .72.

\section{Data Analyses}

Raw data were entered and all data were analyzed using SPSS (Version 14.0). Frequencies and alpha coefficients were computed for all instruments and scales. Pearson product-moment correlation coefficients were computed to examine the relationships among the variables. Multivariate analyses of variance (MANOVAs) were computed to determine possible within-group differences on the basis of gender, ethnicity, and age. Independent samples $t$ tests with a 
follow-up Levene's statistic, to test for equivalence of variances, were computed to compare the participants with a known norm group of younger persons. A Bonferonni's correction was used to control for family-wise error rate, with an alpha coefficient of .002 used to determine significance, and effect sizes were computed for statistically significant findings.

\section{RESULTS}

Means, standard deviations, and ranges computed for men and women and median scores for the total sample are shown in Table 1. Both male and female participants' scores for the second-order factors were lowest on Coping Self and highest on Social Self. The possible range of scores for all scales on the 5F-Wel is 75 . For both sets of participants, the only scale with scores ranging from 25 to 100 was Spirituality, and the next highest range for both was for Exercise, with scores spanning 55 points for men and 50 for women. The lowest range for men was the second-order Coping Self factor; for women, the lowest score range was for the third-order Gender Identity factor followed by the second-order Coping Self factor.

TABLE 1

Means, Standard Deviations, and Range of Scores for Adult Men $(n=50)$ and Women $(n=92)$ Ages 73-101

\begin{tabular}{|c|c|c|c|c|c|c|c|}
\hline \multirow[b]{2}{*}{ Scale } & \multicolumn{3}{|c|}{ Men } & \multicolumn{3}{|c|}{ Women } & \multirow{2}{*}{$\begin{array}{l}\text { Total } \\
M d n \\
\end{array}$} \\
\hline & $M$ & $S D$ & Range & $M$ & $S D$ & Range & \\
\hline Creative & 84.36 & 7.58 & 27.50 & 79.77 & 7.69 & 38.75 & 78.75 \\
\hline Thinking & 83.55 & 9.37 & 25.00 & 78.65 & 8.93 & 43.75 & 75.00 \\
\hline Emotions & 83.00 & 12.05 & 41.67 & 81.58 & 8.73 & 43.75 & 81.25 \\
\hline Control & 84.54 & 9.85 & 31.25 & 78.41 & 8.95 & 43.75 & 75.00 \\
\hline Work & 86.81 & 10.26 & 31.25 & 78.92 & 10.83 & 43.75 & 75.00 \\
\hline Positive Humor & 83.88 & 11.28 & 37.50 & 81.53 & 12.50 & 50.00 & 75.00 \\
\hline Coping & 79.14 & 6.52 & 20.83 & 75.09 & 5.69 & 25.00 & 75.00 \\
\hline Leisure & 82.37 & 11.71 & 35.00 & 83.24 & 9.96 & 35.00 & 80.00 \\
\hline Stress Management & 88.05 & 9.91 & 25.00 & 77.08 & 12.29 & 56.25 & 75.00 \\
\hline Self-Worth & 86.51 & 10.05 & 31.25 & 83.24 & 9.83 & 41.67 & 81.25 \\
\hline Realistic Beliefs & 62.89 & 11.10 & 35.00 & 57.87 & 10.47 & 45.00 & 60.00 \\
\hline Social & 93.42 & 7.93 & 28.13 & 90.55 & 9.33 & 35.71 & 90.63 \\
\hline Friendship & 91.12 & 8.92 & 31.25 & 89.54 & 9.28 & 37.50 & 87.50 \\
\hline Love & 95.72 & 7.53 & 25.00 & 91.71 & 11.73 & 50.00 & 93.75 \\
\hline Essential & 88.65 & 8.61 & 28.33 & 89.47 & 7.67 & 34.38 & 89.06 \\
\hline Spirituality & 87.37 & 17.98 & 75.00 & 87.73 & 15.79 & 75.00 & 90.00 \\
\hline Gender Identity & 95.07 & 9.90 & 37.50 & 98.01 & 4.82 & 18.75 & 81.25 \\
\hline Cultural Identity & 85.86 & 10.38 & 31.25 & 86.36 & 9.37 & 31.25 & 83.33 \\
\hline Self-Care & 85.53 & 10.33 & 33.33 & 85.23 & 9.82 & 41.67 & 100.00 \\
\hline Physical & 85.02 & 10.94 & 35.00 & 83.35 & 11.40 & 45.00 & 85.00 \\
\hline Nutrition & 88.86 & 10.39 & 30.00 & 85.45 & 11.09 & 40.00 & 85.00 \\
\hline Exercise & 81.05 & 18.23 & 55.00 & 81.25 & 15.22 & 50.00 & 85.00 \\
\hline Total Wellness & 85.05 & 6.69 & 22.95 & 82.35 & 6.21 & 30.07 & 81.50 \\
\hline Perceived Stress & 9.00 & 3.28 & 9.00 & 8.56 & 3.22 & 12.00 & 11.00 \\
\hline Total Mattering & 15.53 & 2.50 & 8.00 & 15.29 & 2.66 & 10.00 & 16.00 \\
\hline
\end{tabular}

Note. Creative $=$ Creative Self; Coping $=$ Coping Self; Social $=$ Social Self; Essential $=$ Essential Self; Physical $=$ Physical Self. 
Mean scores higher than the median reflect a positive skew to the distribution, which is seen in the Creative Self, Coping Self, and Social Self factors for men but only on the Creative Self factor for women. The Essential Self and Physical Self scales were not skewed. As a consequence, from a statistical perspective, the mean score is adequate to describe the participants on the second-order factor scores, and also on Total Wellness. When looking at the third-order factor scores, some of the distributions, indeed, appear skewed. For example, the median score on Self-Care was 100. On scales such as these, where the median is higher than the mean, reflecting a skewed distribution, the median may be a better measure of central tendency for the group. Thus, the current data suggest that Self-Care scores for the group as a whole are very high. Similarly, the median score of 16 for mattering suggests that the participants as a whole have a strong sense of belonging in their relationships with others.

Pearson product-moment correlations were computed between all of the scales for all three instruments. No correlations between any of the wellness scales and perceived stress, or between perceived stress and mattering, were significant. In contrast, 11 of the correlations between the 23 wellness scales and mattering were positively and statistically significant $(p<.002)$. These included Total Wellness and four of the five second-order factor scores. Only the correlation between the Physical Self and mattering was not significant.

MANOVAs computed for all scales based on gender resulted in no significant differences. Sample sizes for various cultural backgrounds were insufficient to allow planned comparisons on this variable. To determine possible age differences the sample was split into those under 83 years, the mean age, and those over that age. No significant differences emerged, and cell sizes were too small to permit additional age comparisons. MANOVAs based on marital status were computed with two groups, those married and those not married. Three significant differences resulted. Married persons scored higher than those not married on the Creative Self $(M=80.54, S D=8.21 ; M=75.83, S D=6.79$, respectively; $F=-9.92, p=.002, d=.63)$ and specifically the Thinking factor $(M=82.02, S D=8.87 ; M=75.38, S D=9.22$, respectively; $F=14.24, p=$ $.00, d=.73)$. Married persons also scored higher on Love $(M=93.94, S D=$ 9.04; $M=85.18, S D=14.44$, respectively; $F=15.19, p=.000, d=.73)$. All of these effect sizes were large, as measured using Cohen's $d$.

The 5F-Wel norm group consisted of 3,343 persons (Myers \& Sweeney, 2005 c). For the present study, the 2,017 persons under age 60 in the norm group were used. These persons ranged in age from 18 to 59 years with an average age of 31.25 (SD =12.78). The sample included $42.3 \%$ male participants. Of the participants, $23.5 \%$ had earned a high school diploma, $10 \%$ had earned a bachelors degree, and $12.3 \%$ had earned an advanced degree. A series of independent samples $t$ tests with Levene's statistic calculated to assess homogeneity of variance were computed, and the results are shown in Table 2. Sixteen of the comparisons resulted in statistically significant differences for the wellness factors, none of which 
TABLE 2

Means, Standard Deviations, and $t$ Tests for Adults $73-101(N=142)$

and Adults 18-59 $(N=2,017)$

\begin{tabular}{|c|c|c|c|c|c|c|c|c|}
\hline \multirow[b]{2}{*}{ Scale } & \multicolumn{2}{|c|}{ Adults 73-101 } & \multicolumn{2}{|c|}{ Adults 18-59 } & \multirow[b]{2}{*}{$t$} & \multirow[b]{2}{*}{$d f$} & \multirow[b]{2}{*}{$p$} & \multirow[b]{2}{*}{$d$} \\
\hline & $M$ & $S D$ & $M$ & $S D$ & & & & \\
\hline Creative & 78.94 & 8.17 & 77.18 & 13.81 & -2.34 & 201 & .021 & \\
\hline Thinking & 79.30 & 9.43 & 78.05 & 15.65 & -1.44 & 201 & .152 & \\
\hline Emotions & 79.48 & 10.47 & 76.67 & 15.53 & -2.96 & 185 & .003 & \\
\hline Control & 78.90 & 10.19 & 77.68 & 16.71 & -1.30 & 195 & .195 & \\
\hline Work & 78.16 & 11.23 & 75.49 & 14.05 & -2.63 & 163 & .009 & \\
\hline Positive Humor & 78.77 & 12.13 & 78.19 & 18.48 & -0.53 & 189 & .600 & \\
\hline Coping & 75.43 & 6.58 & 71.60 & 10.82 & -6.35 & 197 & .000 & 0.43 \\
\hline Leisure & 81.66 & 10.84 & 75.15 & 16.48 & -6.62 & 189 & .000 & 0.47 \\
\hline Stress Management & 78.68 & 12.55 & 72.61 & 14.30 & -4.89 & 147 & .000 & 0.45 \\
\hline Self-Worth & 83.36 & 10.64 & 78.54 & 18.83 & -4.83 & 206 & .000 & 0.32 \\
\hline Realistic Beliefs & 59.77 & 10.62 & 61.50 & 12.95 & 1.84 & 171 & .068 & \\
\hline Social & 88.28 & 10.11 & 82.71 & 19.99 & -5.79 & 226 & .000 & 0.31 \\
\hline Friendship & 87.07 & 10.07 & 81.10 & 19.77 & -6.23 & 223 & .000 & 0.38 \\
\hline Love & 89.67 & 13.04 & 84.34 & 21.75 & -4.42 & 196 & .000 & 0.30 \\
\hline Essential & 87.79 & 8.34 & 77.62 & 15.69 & -12.96 & 217 & .000 & 0.81 \\
\hline Spirituality & 86.71 & 15.07 & 74.90 & 20.91 & -8.74 & 180 & .000 & 0.65 \\
\hline Gender Identity & 83.96 & 10.98 & 77.68 & 17.55 & -6.22 & 191 & .000 & 0.43 \\
\hline Cultural Identity & 84.19 & 11.08 & 73.75 & 18.58 & -10.07 & 192 & .000 & 0.64 \\
\hline Self-Care & 95.58 & 7.95 & 83.75 & 19.39 & -14.80 & 274 & .000 & 0.80 \\
\hline Physical & 83.81 & 11.12 & 68.48 & 16.16 & -15.27 & 184 & .000 & 1.11 \\
\hline Nutrition & 85.49 & 11.89 & 67.30 & 17.55 & -16.92 & 186 & .000 & 1.21 \\
\hline Exercise & 82.12 & 15.37 & 69.64 & 20.23 & -9.07 & 174 & .000 & 0.70 \\
\hline Total Wellness & 81.66 & 6.92 & 75.26 & 12.67 & -9.88 & 213 & .000 & 0.63 \\
\hline Perceived Stress & 9.48 & 3.56 & 11.36 & 2.99 & -8.60 & 149 & .000 & -0.57 \\
\hline Total Mattering & 15.42 & 2.89 & 11.10 & 25.94 & -1.83 & 544 & .068 & \\
\hline
\end{tabular}

Note . Creative $=$ Creative Self; Coping $=$ Coping Self; Social $=$ Social Self; Essential $=$ Essential Self; Physical $=$ Physical Self. Cohen's $d$ is provided only for significant results.

included the Creative Self and the third-order factors within this second-order factor. For all of these comparisons, the older adult sample scored higher than the norm group. Effect sizes ranged from medium-for the Coping Self and related third-order factors of Leisure, Stress Management, and Self-Worth, as well as the factors of the Social Self, including Friendship and Love-to large to very large effect sizes, for Total Wellness and the factors of the Physical Self and Essential Self. Perceived stress was significantly lower for the older adult participants than it was for the norm group, with a medium effect size.

\section{DISCUSSION}

This study was conducted to provide a profile of wellness among healthy older adults and to compare wellness and correlates of wellness among the older adults with younger persons. As expected, based on the literature, overall, the participants reported a high level of wellness as reflected in mean scores. The results reveal both within- and between-group differences that together suggest the possibility 
of both developmental factors associated with wellness and factors associated with greater wellness among older adults than in their younger counterparts.

Scores for the 5F-Wel are mean item responses for each scale placed on a common metric ranging from 25 to 100 . For a given item, a score of 25 would roughly correspond to strongly disagree, 50 would correspond to disagree, 75 would correspond to agree, and 100 would correspond to strongly agree. Mean scores for the participants on most of the wellness scales were uniformly above .80 , suggesting that taken as a whole these older adults rated their personal wellness in most areas as quite high. This finding is supported by the low range of scores for Total Wellness for both men (22.95) and women (30.07).

The possible range of scores for each scale is 75 , yet for both men and women, the full range of scores was achieved only for the third-order factor of Spirituality. For men, only a 25-point spread of scores resulted for the Thinking factor, Stress Management, and Love. For women, the range of scores on Gender Identity was very low, 18.75 , and the range for the Coping Self was 25 . The range restriction evidenced here reflects the homogeneity of the sample, a group of persons residing in one location who were predominantly European American, well-educated, and financially stable. Although the participants were intentionally selected to represent one particular and likely homogeneous group, the score ranges need to be considered in examining the meaning of the current scores. Median scores are also important because even with a high mean, a lower median reveals that half of the group could be at risk in any particular area of wellness.

It is noteworthy that both men and women scored highest on the Social Self factor, which includes both Friendship and Love. The items on these scales assess the presence of significant others with whom one feels close or intimate and who provide needed emotional, informational, and material support. In the upscale retirement setting where the participants reside, social networking is highly valued, and numerous activities are provided that bring residents together for social and intellectual pursuits. We noted the high level of participation when we visited the facility to present a workshop on wellness in order to help the residents understand their scores. The workshop was sponsored by the wellness committee, and approximately 250 residents attended. This is about one third of the total number of residents in the facility, including residents in independent and assisted living and skilled nursing care. A high level of energy and an extended question-and-answer session revealed their interest in the subject. It is possible that, even for the one third of participants who were widowed, the efforts of volunteers and staff to help those without significant others feel involved and included were being quite successful.

The lowest scores on the second-order factors for both men and women occurred for the Coping Self. This factor includes the third-order factors of Leisure, Stress Management, Self-Worth, and Realistic Beliefs. The mean scores for Realistic Beliefs were the lowest of any of the third-order factors, which Myers and Sweeney (2005c) noted is consistent for all populations. They attribute this finding to the nature of the factor, which assesses needs for perfection 
as defined by Ellis (1973), including the need to be liked or loved by everyone one meets and the need to do all things well in order to feel worthwhile. A review of the mean scores in Table 1 suggests that the remaining third-order factor means are not low in relation to all other 5F-Wel scale means.

Although examining mean scores gives a good indication of populations as a whole, it is important to remember that many people score below the mean. Moreover, wellness is truly a holistic characteristic, and the high correlation among wellness factors suggests that an individual who scores low in one area will also score low in other areas (Myers \& Sweeney, in press). A review of the standard deviations and range scores in Table 1 underscores the fact that, although the participants were homogeneous in many ways, significant withingroup variability existed. In some instances, the median score for the total group was lower or much lower than the mean for either men or women or both (e.g., Thinking, Control, Work, and Positive Humor). Such findings suggest that while a number of the older participants experienced high levels of wellness in these areas, at least half experienced moderate to low levels of wellness. Furthermore, for those persons who score particularly low in one or more areas of wellness, overall quality of life and life satisfaction, factors known to be associated with positive wellness (Myers \& Sweeney, in press), may indeed suffer.

An examination of mean scores for the Perceived Stress Scale shows range restriction for men but not women with similar means for both. These mean scores are not particularly high, a finding perhaps explained by the Stress Management scores seen on the 5F-Wel. Not only were the mean Stress Management scores high, but the scores for men were higher than those for females. Higher perceived stress and lower perceptions of one's stress management wellness are theoretically and usually practically consistent. The low alpha for the PSS is also a consideration that argues for caution in interpreting the data and likely resulted from the small number of items in this scale.

Similarly, although mattering scores may range from 4 to 20 , or over a 16point spread, the scores of the men in the current study ranged over only 8 points and for women over 10. These findings are consistent with the higher scores for the Social Self, because both factors measure some aspects of having positive interpersonal relationships.

The strong relationship among mattering and the 11 wellness factors provides new evidence for the supposition that there is a strong relationship between social support and mental health in older adulthood, as noted by Blazer (2005) and YueJuan et al. (2005). All of the second-order factors, except for the Physical Self factor, were significantly related to mattering. This is strong evidence for the importance of social networks in later life. In addition, those participants who were married had higher levels of the Thinking factor, suggesting that mental fitness may be positively influenced through involvement in a significant relationship with another. It is interesting that perceived stress was not significantly related to any wellness factor, including Stress Management. This population may have been unique in that the 
typical causes of stress for older adults were minimized due to their robust financial situation, strong community involvement and support, or other unique factors.

Comparisons between this select sample of well, older adults and a norm group of adults ages 18 to 60 provide an initial look at possible developmental differences in wellness. The younger persons were more heterogeneous on all demographic factors examined: age, ethnicity, and so on. It is not surprising, then, that the mean wellness scores of the younger adults were almost uniformly significantly lower than those for the older adult sample. The main exception was the Creative Self second-order factor and each of the associated third-order factors: Thinking, Emotions, Control, Work, and Positive Humor. On these scales, there were no differences based on an alpha of .002, although a more liberal measure of significance would yield different findings for Emotions $(\mathrm{alpha}=.003)$ and Work $($ alpha $=.009)$. Work may not be as germane to a group of retirees as other factors may be, although we attempted to minimize this factor through wording related to meaningful activities rather than work per se. Control is also a factor within the Creative Self, and the smaller discrepancy between the participants and the norm group may reflect a more restricted lifestyle in contrast to the participants' lives preretirement. It is also noteworthy that there were no differences between the younger and older samples on Realistic Beliefs, supporting Ellis's (1973) contention that the need for perfection is universal.

Older adults, ideally, will have developed a greater sense of identity and perspective than younger adults, and these may be indicated by their significantly higher wellness levels regarding the Essential Self. This factor includes Spirituality, Gender Identity, Cultural Identity, and Self-Care. As older adults grow increasingly aware of their mortality and the necessity of addressing end-of-life issues, strong levels of spiritual wellness may play an important role in their ability to meet these challenges. For this older group of participants, their retirement setting ensures that they are able to socialize with others who are similar to themselves, which in itself may positively enhance their level of the Cultural Identity wellness factor. Also, the high level of Self-Care may also be contributed to by the retirement setting. This study provides support for the benefits that may arise from living within a community that is focused on healthy aging and that makes wellnessoriented activities available to its residents. The social support to be found in such a retirement setting may also be reflected in the higher level of wellness in the Social factor. Although married participants had higher levels of wellness for the Love factor, the entire group had significantly higher levels of Social wellness than the norm group.

Physical wellness levels were markedly higher among the participants than for the norm group. This may reflect the importance of making healthy nutritional choices for specialized diets that may come with medical conditions. These older adults may have scored higher on Exercise, because they may have more time to devote to exercise than the norm group did, as well as live in a setting that offers easily accessible exercise and fitness facilities. Unfortunately, 
many older adults may not have the financial means or the physical capacity to enjoy comparable levels of nutrition and physical wellness. Within the Coping Self factor, the participants' scores on Leisure and Stress Management may reflect their current living situation as retirees with more leisure time; they are residents in a community that offers multiple activities in which they can participate. Stress management may be less of an issue for older adults in comparison with younger adults because older adults no longer must handle as many roles as they might have handled prior to retirement. Overall, these results offer evidence that healthy aging is possible and that older adulthood may offer a greater sense of wellness than individuals experienced in earlier decades.

The overall snapshot of this group of participants indicates that older adulthood can be a time of enhanced overall wellness as evidenced in the higher levels of wellness found as compared with the younger norm group. These findings may be due to some unique characteristics of the current participants. Generalizability of the research findings will certainly be affected by the voluntary nature of participation and the fact that the participants were so homogeneous on many demographic indices. At the same time, a significant subgroup reported lower levels of wellness, so an assumption of universal higher wellness in this more upscale sample of older adults is not warranted. An important focus for future research is exploration of possible differences between ethnic and socioeconomic groups, which was not possible in the current study. However, these findings do suggest that older adulthood does not have to be a time of compromised health and well-being.

\section{IMPLICATIONS FOR COUNSELORS}

The results of this study suggest that strong levels of wellness, across a variety of realms, and a sense of mattering can be found among adults in various stages of the aging process. Thus, counselors should be aware that "old age" does not automatically equate to frailty and diminished emotional/mental well-being. Recognizing the strong relationships between specific areas of wellness and mattering, counselors should assess social relationships and support early in their work with older adult clients. A sense of belonging, or mattering, may play a large part in the desire to optimize wellness and to maximize involvement in health-promoting activities. Isolation and lack of social involvement can be both symptoms and causes of depression in the older adult population, so it may be useful for counselors to assess older clients for any signs of this mood disorder. Finding ways to promote Social Self wellness may be an important way to help overcome depression.

Although it is tempting to use mean scores to describe a group of people, in this instance older adults, and make conclusions based on central tendency, it is also important to note the variability that occurred within this group of participants. Although range restriction occurred on multiple scales, the fact that many of the participants received lower scores on scales such as Spirituality and Exercise merits further consideration. Even in an upscale setting, with higher levels of education and 
income apparent, and with high levels of social support and lower perceived stress levels reported, there remained individual older adults at risk for lower levels of wellness or compromised wellness whose wellness needs to be carefully assessed across multiple domains as a foundation for planning needed interventions.

Wellness scores for groups of older adults, such as those presented here, can be used as the basis for planning programs and interventions to enhance wellness in a given area. The current group of participants used their group wellness scores to select guest speakers on topics of interest, such as positive humor, in order to increase their wellness in this area. Counselors working with the same population might use the scores to develop psychoeducational programs, in this or other areas, to help the older adults explore ways to increase their wellness as well as the personal meaning of wellness. Caution is urged with this approach, however, because it begins with an examination of mean differences that, as discussed earlier, may function to obscure the significant issues faced by persons with lower scores who may be at risk for poor physical and mental health.

Identifying persons who experience low levels of wellness in one or more areas may be accomplished with formal wellness assessments as used in this study. One advantage of this type of assessment is that persons with low wellness levels may be identified as needing counseling interventions. For example, although the mean Spirituality score was 87 for both men and women, 2 participants received a score of 25 , the lowest possible score; 1 scored 35 ; and 1 scored 40 . Clearly, these persons merit closer attention. They could be having a personal spiritual crisis, perhaps precipitated by a significant personal loss. Spirituality deals with more than organized religion and includes perceptions of purpose and meaning in life. These individuals could benefit from individual counseling interventions to help them reestablish a sense of meaning and purpose in life. Similarly, although mean scores for Friendship were very high, 1 participant received a score of only 50 , and 6 others scored in the low-60s. These persons might benefit from counseling to help them explore their social networks and develop those networks in a positive manner.

Wellness scores can be used to screen older individuals to identify those most in need of helping interventions, both individual and group. High scores also can be used to identify strengths. Thus, both low and high scores may provide an initial focus for counseling. Older adults may be reluctant to seek counseling but may be more comfortable when counseling begins with an objective and positive focus. Wellness scores can provide that focus. As we saw in our followup psychoeducational intervention, the topic of feeling better in a holistic sense was one that the older participants approached with enthusiasm and energy.

The finding that the current sample of older adults experienced higher levels of wellness than did adults younger than age 65 may mean that there is a developmental component in wellness or simply that older persons become more concerned with functioning well based on their life circumstances and overall health. Counselors working with older adults should bear in mind that their clients may have developed a wide repertoire of coping skills over the course 
of their lifetimes but that new skills may be needed to face new challenges. Helping older adults to reflect on their wellness when they were younger can give the counselor important information about the dynamics of wellness across the life span. What is implied here is that counselors may expect to learn a lot from their older clients. By inviting the client to share past methods of coping with life's developments, the counselor can help the client determine his or her own best course of action based on past experience and new perspectives.

The role of stress has been emphasized as an area of significance in the lives of older adults (e.g., Moos et al., 2005). Given the current finding of a median score of only 75 for a highly educated, higher socioeconomic-level group of older adults, with half of the participants scored below that level, counselors are encouraged to investigate their older adult clients' stress levels via informal or formal assessments and their stress management resources. Often, new resources can be developed and need to be developed to cope with the challenges of later life. By helping older adults gain control over significant life stressors, counselors may allow them to focus on taking action to improve other areas of functioning.

\section{CONCLUSION}

In conclusion, this study provides additional evidence that older adults benefit from social engagement and mental activity and that healthy aging is indeed an achievable aspiration. Encouragement should be given to this population to develop and maintain social connections within their communities and to other age groups to provide opportunities to interact with older adults in their lives. These connections would provide increased opportunities for enhanced wellness and a sense of belonging for this age group, which would contribute to the "healthy aging" that will become increasingly crucial as society's aging population grows. Additional studies of wellness among subgroups of the older population are encouraged to help older adults as well as counselors understand the changing dynamics of wellness across the life span and especially in the later years.

\section{REFERENCES}

Amundsen, J. M. (1993). Psychotherapy and meaning: Toward a theory of pastoral psychotherapy. Dissertation Abstracts International, 54(1-B), 473.

Anhus, J., \& Reeve, P. (2006). Ageism: A threat to "aging well" in the 21st century. The Journal of Applied Gerontology, 25, 137-152.

Atkinson, D. R., \& Hackett, G. (1998). Counseling diverse populations (2nd ed.). New York: McGraw-Hill.

Blazer, D. G. (2005). Depression and social support in late life: A clear but not obvious relationship. Aging and Mental Health, 9, 497-499.

Cohen, S., Kamarck, T., \& Mermelstein, R. (1983). A global measure of perceived stress. Journal of Health and Social Behavior, 24, 385-396.

DeForge, B. R., \& Barclay, D. M. (1997). The internal reliability of a general mattering scale in homeless men. Psychological Reports, 80, 429-430.

Degges-White, S., \& Myers, J. E. (2006). Transitions, wellness, and life satisfaction: Implications for counseling midlife women. Journal of Mental Health Counseling, 28, 133-150. 
Degges-White, S., Myers, J. E., Adelman, J. U., \& Pastoor, D. (2003). Examining the counseling needs of headache patients: An exploratory study of wellness and perceived stress. Journal of Mental Health Counseling, 25, 271-290.

Dixon Rayle, A. D., \& Myers, J. E. (2004). Wellness in Adolescence: The roles of ethnic identity, acculturation, and mattering. Professional School Counseling, 8, 81-90.

Dunn, H. L. (1961). High-level wellness. Arlington, VA: Beatty.

Dunn, H. L. (1977). What high level wellness means. Health Values: Achieving high level wellness, 1, 9-16.

Ellis, A. (1973). Humanistic psychotherapy: The rational emotive approach. New York: Julian.

Hagerty, B. M., \& Williams, R. A. (1999). The effects of sense of belonging, social support, conflict, and loneliness on depression. Nursing Research, 48, 215-219.

Hattie, J. A., Myers, J. E., \& Sweeney, T. J. (2004). A factor structure of wellness: Theory, assessment, analysis, and practice. Journal of Counseling o Development, 82, 354-364.

Larson, D. D. (1999). The conceptualization of health. Medical Care Research and Review, 56, 123-136.

Marcus, F. M. (1991). Mattering: Its measurement and theoretical significance. Unpublished manuscript.

Marcus, H. R., \& Kitayama, S. (1991). Culture and the self: Implications for cognition, emotion, and motivation. Psychological Review, 98, 224-253.

Moos, R. H., Schutte, K. K., \& Brennan, P. L. (2005). The interplay of life stressors and depressive symptoms among older adults. Journals of Gerontology: Series B: Psychological Sciences and Social Sciences, 60B, P199-P206.

Myers, J. E. (2003). Coping with caregiving stress: A wellness-oriented, strengths-based approach for family counselors. The Family Journal, 11, 1-9.

Myers, J. E. (2005). Wellness in later life: Research implications. In J. E. Myers \& T. J. Sweeney (Eds.), Counseling for wellness: Theory, research, and practice (pp. 99-104). Alexandria, VA: American Counseling Association.

Myers, J. E., Madathil, J., \& Tingle, L. R. (2005). Marriage satisfaction and wellness in India and the United States: A preliminary comparison of arranged marriage and marriages of choice. Journal of Counseling \& Development, 83, 183-190.

Myers, J. E., \& Mobley, K. A. (2004). Foundations of wellness promotion for undergraduate students: Lessons from between and within groups comparisons. Journal of College Counseling, 7, 40-49.

Myers, J. E., \& Sweeney, T. J. (2005a). The Five Factor Wellness Inventory. Palo Alto, CA: Mindgarden.

Myers, J. E., \& Sweeney, T. J. (2005b). The Indivisible Self: An Evidence-Based Model of Wellness. Journal of Individual Psychology, 61, 269-279.

Myers, J. E., \& Sweeney, T. J. (2005c). Manual for the Five Factor Wellness Inventory. Palo Alto, CA: Mindgarden.

Myers, J. E., \& Sweeney, T. J. (Eds.). (2005d). Wellness in counseling: Theory, research, and practice. Alexandria, VA: American Counseling Association.

Myers, J. E., \& Sweeney, T. J. (in press). Wellness counseling: The evidence base for practice. Journal of Counseling \& Development.

Myers, J. E., Sweeney, T. J., \& Witmer, J. M. (2000). The Wheel of Wellness counseling for wellness: A holistic model for treatment planning. Journal of Counseling o Development, 78, 251-266.

Peel, N. M., McClure, R. J., \& Bartlett, H. P. (2005). Behavioral determinants of healthy aging. Journal of Preventive Medicine, 28, 298-304.

Powers, A., Myers, J. E., Tingle, L., \& Powers, J. (2004). Wellness, perceived stress, mattering, and marital satisfaction among medical residents and their spouses: Implications for education and counseling. The Family Journal, 12, 26-36.

Rosenberg, M., \& McCullough, B. C. (1981). Mattering: Inferred significance and mental health among adolescents. Research in Community and Mental Health, 2, 163-182.

Schlossberg, N., Lynch, A. Q., \& Chickering, A. W. (1989). Improving higher education environments for adults. San Francisco: Jossey-Bass.

Sweeney, T. J., \& Myers, J. E. (2003). The Indivisible Self: An Evidence-Based Model of Wellness. Greensboro, NC: Author.

U.S. Administration on Aging. (2005). A profile of older Americans. Retrieved May 12, 2006, from http://www. aoa.gov/PROF/Statistics/profile/2005/profiles2005.asp

World Health Organization. (1952). Constitution of the World Health Organization (5th ed.). Palais des Nations, Geneva: Author.

Yue-Juan, Z., Yun-Jing, S., \& Zeng-Qli, W. (2005). Moderator effect of social support and cognitive style on relationship between stress and depression. Chinese Mental Health Journal, 19, 655-658. 